national country life federation will commend itself to all the associations, institutions, and departments which the proposed constitution would invite to adhere and be represented by sending delegates to the national federation. The power which these constituent organizations will bring to the federation will prove to be marvelous. Our special and general country life associations, our agricultural colleges, experiment stations, and departments, including our farm women's associations and institutions, will supply trained and seasoned leaders, which in this general organization will find opportunities to help crystallize and put forward the mighty things to be desired by our great farm people.

Nowadays a decade witnesses the culmination of accomplishments larger than were achieved during the entire century recently closed. May it not be that the building up of the open country so as to build up the heredity of the races of man is to be at least one of the achievements of the twentieth century?

Truly the proposed new Country Life Federation has before it more problems than the increasing of the products of the soil. It can help to produce a new civilization based on truly efficient people.

\title{
HORSES AND HORSE BREEDING
}

\author{
H. K. Bush-Brown \\ Washinglon, D. C.
}

It is a curious thing that fossil remains of the horse are found on this continent where the race had become extinct ages before its discovery by Columbus. On the other hand the living horse is indigenous to Africa, Europe or Asia, but as to just where, authorities differ greatly.

Whether all horses living are of one family or may be divided into four families or more, is perhaps of little interest to the breeder. He has his own ideas of differentiations as he sees them. No matter how insistently science may claim a common ancestry for the horse no breeder will ever recognize the zoölogical law to such an extent as to try to breed draft horses from Shetland ponies, for instance. If, as some claim, these wide differences of type are largely of man's selective creation, so much the more important it is to study them, if the breeders are to take advantage of variations in creating atill other types adapted to the needs of man. In this connection I 


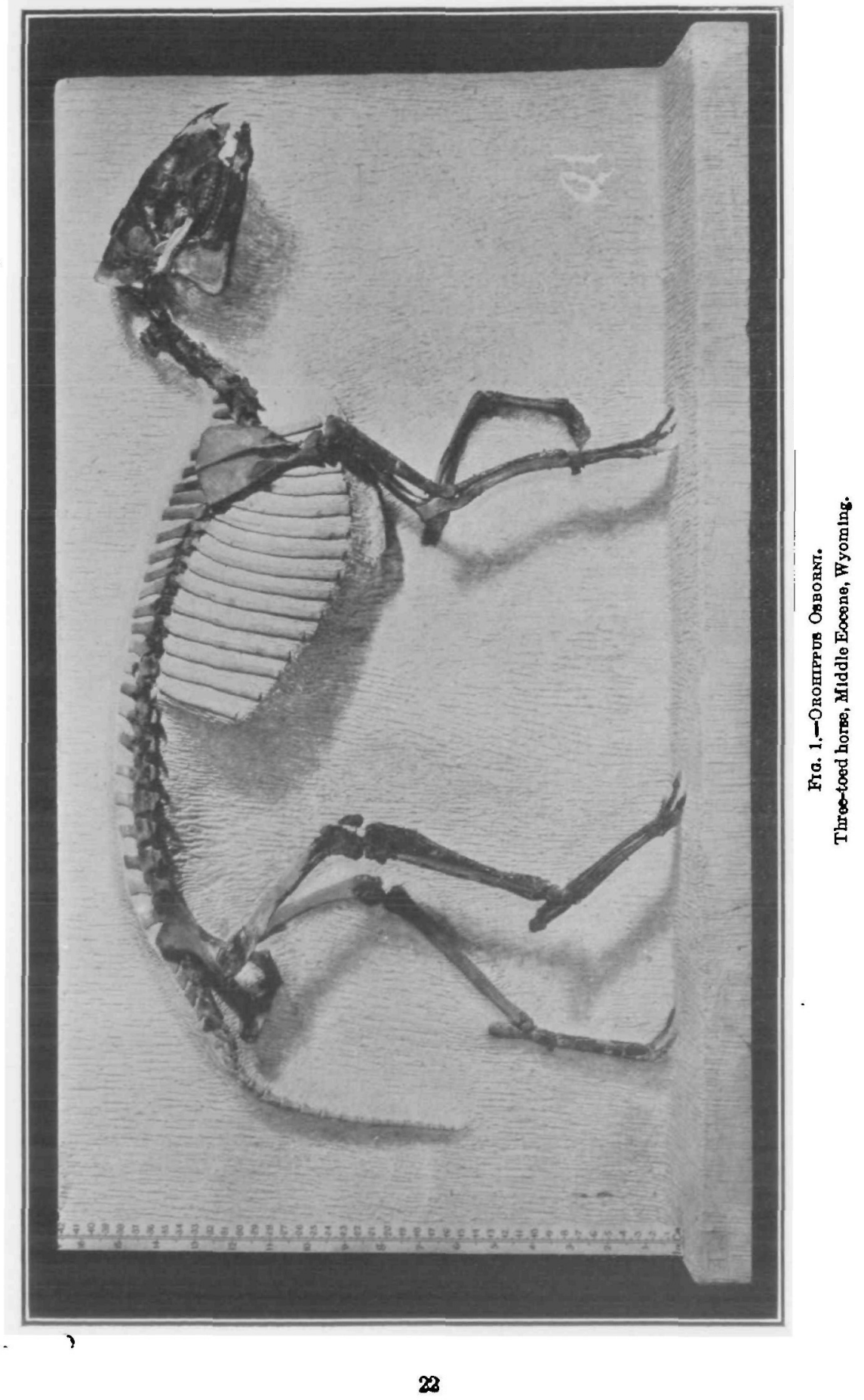

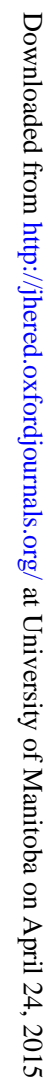


would ask for a continued study of anatomical variations that are known to exist, for in the process of evolution of the horse, nature has done and is still doing some interesting things with the bony structure of that animal.

Great was the excitement in the field of science some years ago when Prof. O. C. Marsh of Yale discovered in rock strata on the western ridge of our continent fossil remains of a three-toed and a four-toed horse. If we look carefully at these specimens now in the Museum of Natural History in New York, we will find that the three-toed horse has eight lumbar vertebrae (see Fig. 1); the early

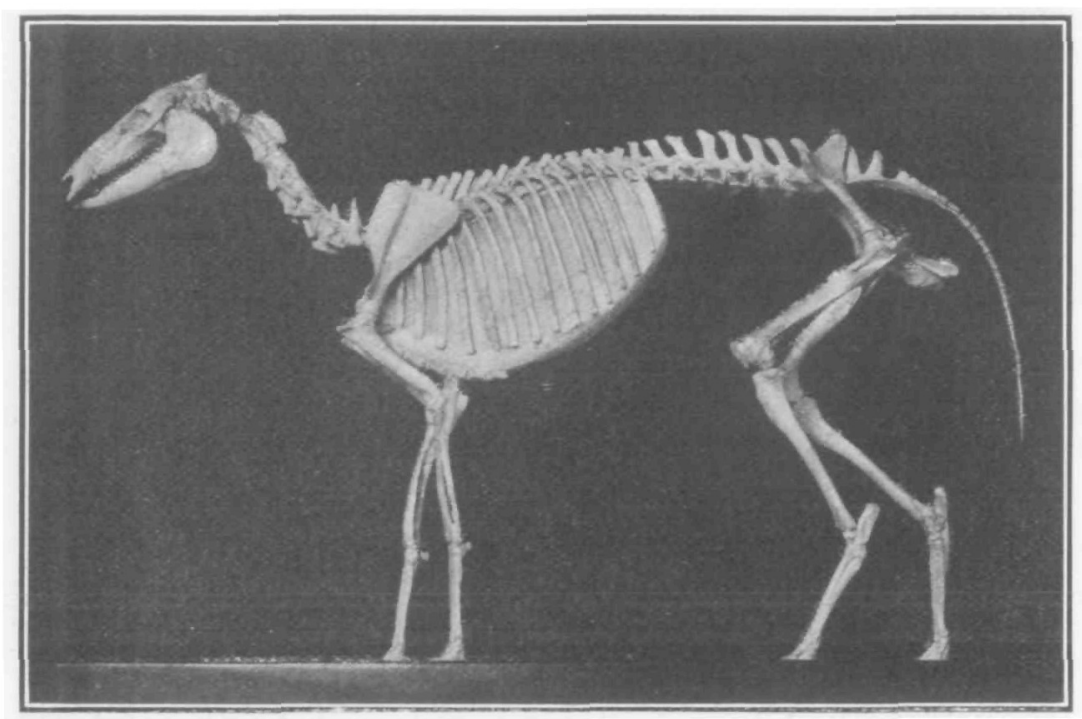

Fia. 2.-M morippus BaIAdi.

Three-toed horee, Oligooene Epoch, Bouth Dakota.

three-toed horse seven (see Fig. 2). The Neohipparion, a more advanced three-toed horse, has but six. The fossil Scotti horse found in Texas, six (see Fig. 4); the forest horse of Europe as represented by a skeleton of a Percheron has six (see Fig. 6); Henry Clay, an ancestor of the American Trotters, had six (see Fig. 5); and the Arab horse has only five (see Fig. 10, p. 93, American Breeders Magazine, vol. ii, no. 2). Thus the higher the type the fewer the bones in his loins.

Now let us follow in the same manner the bones of the foreleg. Figure 1, the three toes (fossil). Figure 2, the three toes (fossil). 
Figure 4 the Scotti horse (fossil),"-showing only one toe and the two others reduced to nearly the size of the splint bones of the modern horse. Figure 5 the modern horse, Henry Clay, has splint bones more slender. Apparently here obtains the same law of elimination of superfluous bones as the higher types are approached.

On these lines Mr. Chubb of the Museum of Natural History in New York has made some discoveries that ought to be of interest and of material use to horse breeders. It has been known for some time that occasionally there is found on the foreleg of the horse an eighth carpal in very vestigial form. These carpals are the set

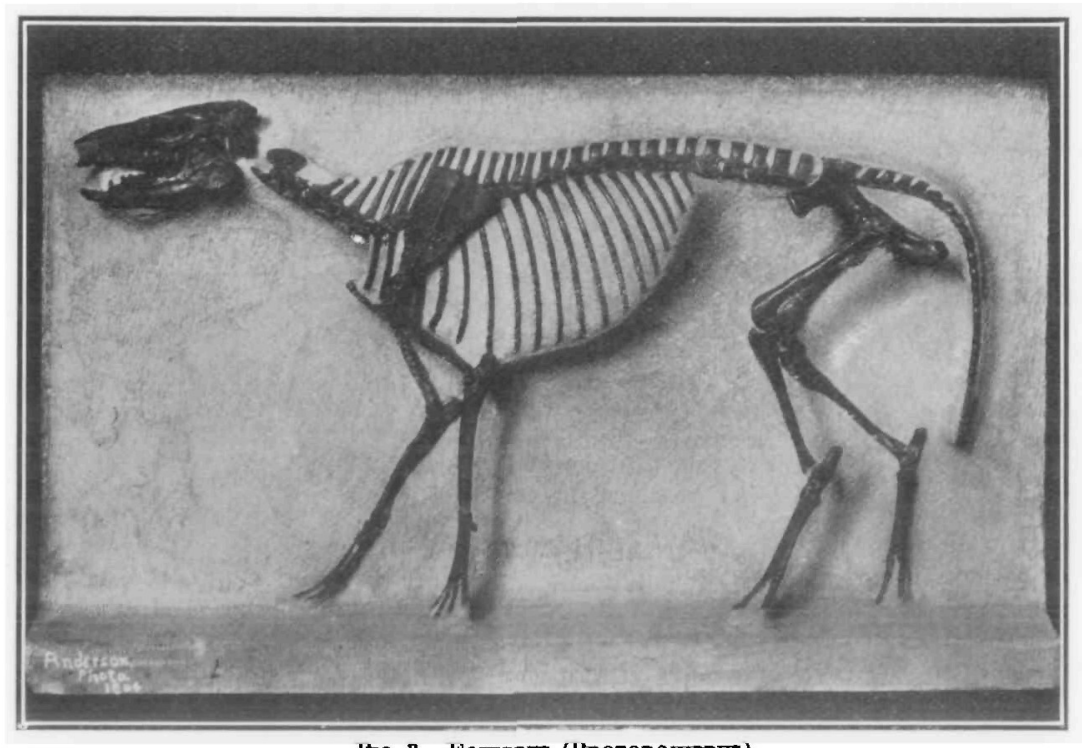

FIO. 3.-EOHPPUB (РROTOROHIPPUB).

Four-toed hores, Iower Eocene, Wyoming.

next above the cannon bone. The first one in the distal (remote from point of attachment) row is the trapezium bone and is so small that it is difficult to find, being frequently overlooked when it does exist. This bone varies a great deal in size and shape, the largest about three-quarters of an inch long and tooth shaped. Wishing to know something about this little bone, Mr. Chubb obtained a number of horse knees from Barren Island and found the bone pres-

\footnotetext{
It Fill be of Interest to breeders to know that the fosell memain of the Scotti forse were discovered in Texas by J. W. Gidley. They are akeletons of young horses about a year old as indicated by their weth, and as they are large for their age they must have been about the sire of a draft hore when mature.
} 
ent in 57 per cent of those examined. In one case, however, the bone was so placed that it impinged to such an extent on the trapezoid whenever the knee was bent that an irritation was set up and part

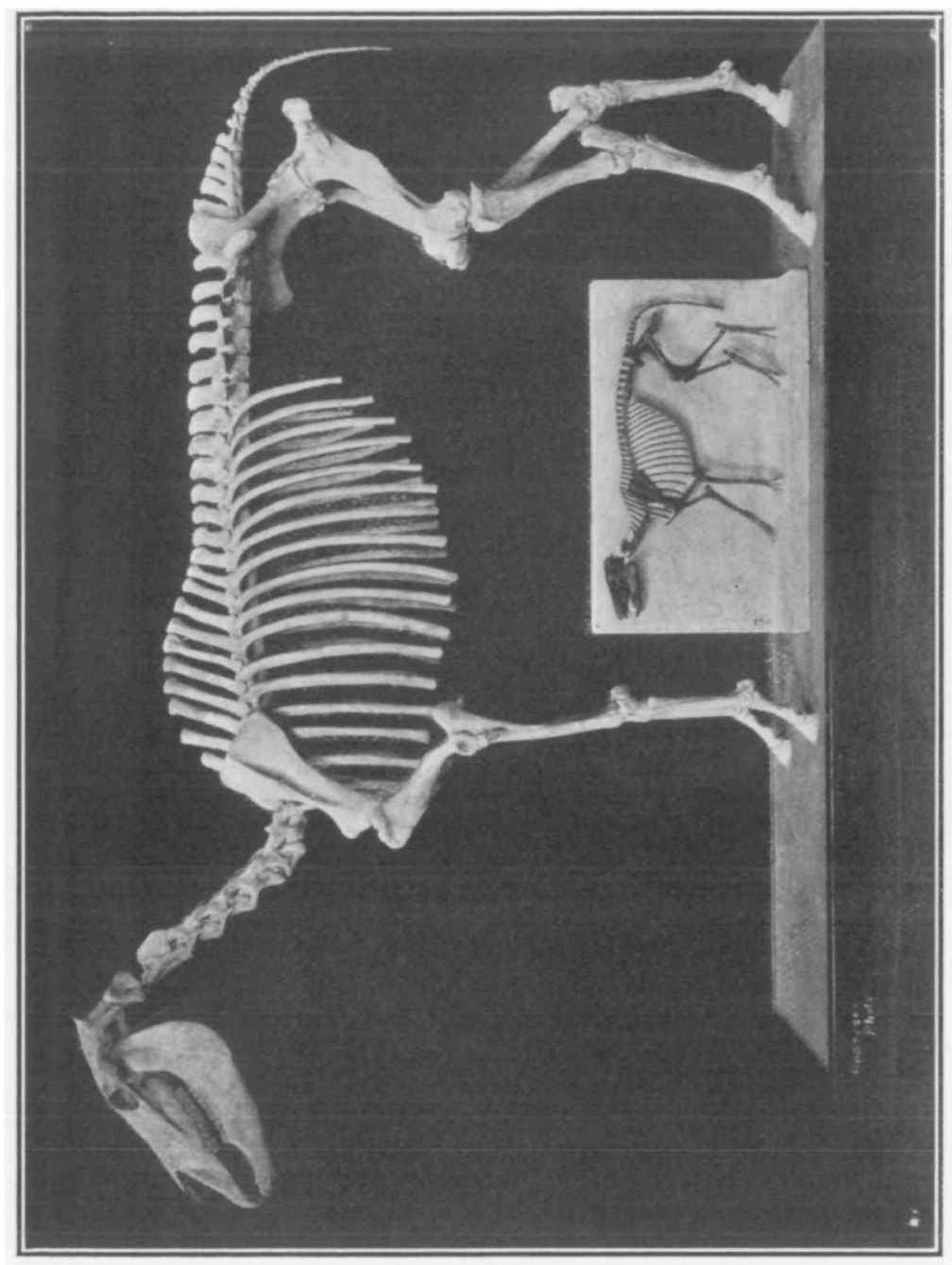

of the bone absorbed in order to make space for the little trapezium. Unfortunately for breeders, Mr. Chubb took his material indiscriminately and made no selection of the several horse types in obtaining his specimens. 
It would be very interesting to breeders to know if the law of elimination of this extra bone in the leg prevails with approach to the higher types, as appears to be the case in the vertebrae. Knowl-
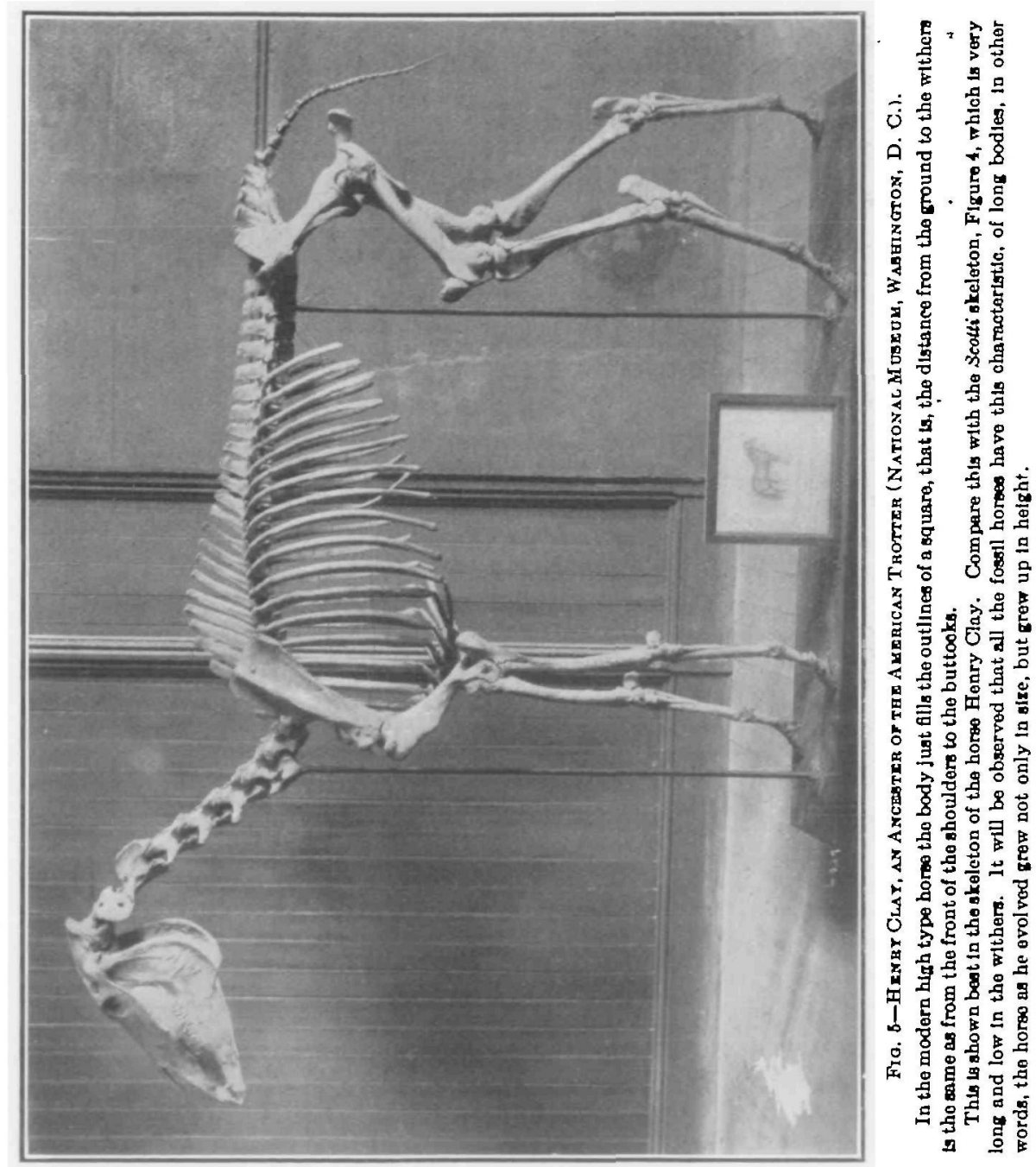

edge on this subject should be of interest to veterinarians and horse breeders, for it is conceivable that if a race horse possessed a trapezium bone so large as to bump on the trapezoid bone every time he folded his knee he would be perceptibly impeded, if he did not in some cases 
actually become lame every time he did really severe work. Among the specimens examined by Mr. Chubb he found one with still another vestigial carpal about the same shape and size as the eighth mentioned above. This is the only one on record and it suggests that the evolution of the horse is still going on, and that there are variations which may be individual, or which may belong to one specialized type.

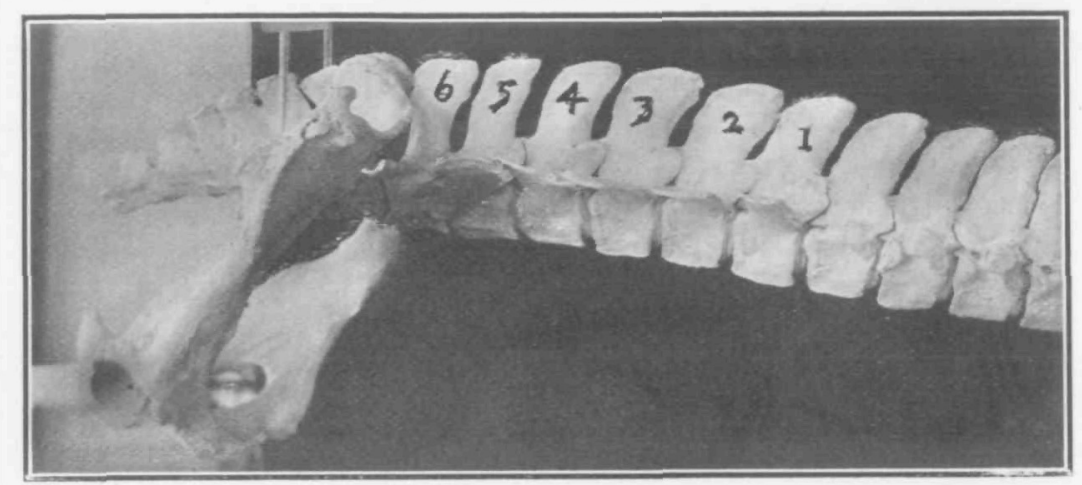

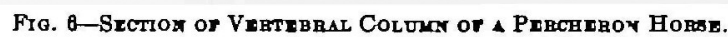

Showing alx Lumbur Vertebrae. Husenm of Natural Htatory, Now York.

If societies of horse breeders would take up the study of comparative anatomy of the several types of horses it seems likely we would learn something about horses which we do not know now. These trapezium bones may perhaps occur only in the mongrel horse and may rarely or never be found in specialized types of trotters, thoroughbreds or Arabs, but we do not know.

\section{COLOR FACTORS IN THE HAIR OF THE HORSE}

\section{J. M. EgLOFP \\ Cedar Falls, Iowa}

There has been much work done of late on the general question of inheritance of color in horses and many opinions have been advanced in regard to the basis of color. Many of these have been mere guesses instead of a careful study such as ought to characterize all scientific investigations.

With the object in view of learning if possible what really does determine or constitute color, the writer conducted the following investigation.

Thirty-three specimens of hair were collected from the various veterinary colleges located in different parts of the United States. 